\title{
Urgences
}

\section{Poèmes pour accompagner des photographies tunisiennes de Lorand Gaspar}

James Sacré

Numéro 33, octobre 1991

Poésies parallèles : France - Québec

URI : https://id.erudit.org/iderudit/025671ar

DOI : https://doi.org/10.7202/025671ar

Aller au sommaire du numéro

Éditeur(s)

Urgences

ISSN

0226-9554 (imprimé)

1927-3924 (numérique)

Découvrir la revue

Citer ce document

Sacré, J. (1991). Poèmes pour accompagner des photographies tunisiennes de Lorand Gaspar. Urgences, (33). https://doi.org/10.7202/025671ar d'utilisation que vous pouvez consulter en ligne.

https://apropos.erudit.org/fr/usagers/politique-dutilisation/ 


\section{James Sacré}

Claude Beausoleil 


\section{Poèmes pour accompagner des photographies tunisiennes de Lorand Gaspar \\ James Sacré}

Ce qu'on ressent d'abord c'est qu'on pourrait surtout se perdre dans cela qui est parfaitement dessiné mais si massivement fragile (et ça n'en finit pas de se défaire),

Se perdre aussi bien dans les sables

Que dans l'emportement lent des nuages.

Les deux étendues, où cherche le regard, sont habitées du même vide insaisissable (le vent mêlé au temps); on aimerait pouvoir être la tranquillité très mince des dromadaires qui s'en vont passer par l'horizon.

Où rien de plus précis, pourtant, ne paraît 
Le noir et blanc comme un œil

Qui passe à travers les couleurs Avec sans doute un désir D'éternité.

L'éternité comme un leurre.

Une koubba ressemble un peu

À la boîte de l'appareil photo.

Et la photo resterait

Où le monde est visible pour de vrai.

Maintenant le regard du poème Comme un objectif ouvert:

La photo sans fin là devant

Où elle est visible pour de vrai. 
90

Ce qu'il y a sur la photo se trouve parfois

Comme tout près des yeux: on viendrait par exemple De participer à la construction de ce qui est au premier plan, on s'écarte un peu

Pour vérifier l'appui d'un léger dôme sur une assise trapue;

L'ensemble arrange des endroits d'ombre avec les fins couteaux de la lumière

Et dans ce plaisir d'être à la bonne distance pour apprécier

Viennent aussi des choses qui sont beaucoup plus loin,

Belle profondeur de champ dans la photo et celle

De la mémoire et du cœur, rien qui reste

À la seule surface des yeux, celle de l'histoire

Immense et matériau modeste (sans doute que l'éternité est fragile) on n'est plus très sûr

De ce qu'est le temps; l'envie

De caresser cette photo. 
On s'assoit à l'ombre d'un mur dans le temps qui vient Mais tout aussi bien dans le plein soleil. On attend. On n'attend rien.

On regarde longtemps devant soi pour savoir à la fin (on le savait déjà)

Que la couleur du jour est l'essentiel, ou celle

D'un petit bâtiment blanc tout seul

Comme dans une prière au dieu qu'on dit être le seul; qui est le monde,

Et peut-être rien d'autre. La solitude est un mot vide.

Le petit bâtiment strict. Comme un cœur silencieux. Comme de la pierre et de l'esprit. Même si le sable l'envahit. 
L'éternité comme un clin d'œil

Pour échapper au temps Avec sa couleur qui change Le photographe... etc.

La photo voudrait quoi garder? 